\title{
Carta de Presentación
}

El primer número del Journal de Ciencias Sociales, revista académica de ciencias sociales de la Universidad de Palermo, presenta una colección de artículos escritos por autores que provienen de diferentes geografías y reflexionan sobre diversos temas: los tipos de investigaciones que se producen en ciencias sociales, las "buenas sociedades", la diáspora de grupos étnicos y religiosos, las políticas de juventud, la recuperación histórica de la cultura, las vivencias de la espacialidad y la tenencia del suelo.

La revista se inicia con el artículo Investigar en ciencias sociales: el desafío por el análisis científico en el cual Graciela Castro nos habla de la necesidad de revisar lo que sucede en las ciencias sociales acerca de los problemas de investigación, los paradigmas teóricos y metodológicos y el impacto de las investigaciones en su relación con el mundo público y el académico; siendo este ensayo el resultado de prácticas investigativas de la autora, de las cuales devienen reflexiones que procuran pensar la investigación como una tarea estrechamente vinculada con las demás funciones que competen a la vida académica, incorporando el reconocimiento de la influencia del contexto histórico, científico y político en América Latina.

Desde Italia, Filomena Maggino nos presenta su artículo que se titula The good society: defining and measuring wellbeing between complexity and limit y en el cual se comenta que investigadores de todo el mundo han dedicado años trabajando activamente en la definición de conceptos y medidas acerca del bienestar. En este sentido y para definir que es una "buena sociedad" (good society) es necesario tener en cuenta dos conceptos: complejidad y limites. En este artículo se intenta proveer una interpretación acerca de los instrumentos que se han utilizado, a fin de ayudar a la diferenciación entre las propuestas emergentes: las serias y las meramente propagandísticas.

A continuación y desde México, Karla Valverde Viesca, escribe sobre la Reforma y políticas juveniles en México: avances y retrocesos institucionales, explicando cómo el proceso de reforma impulsado durante la década de los ochenta, privilegió en México la liberalización económica y la consolidación del ámbito político-electoral, aplazando la construcción de un andamiaje institucional para diseñar e instrumentar políticas, planes y programas asociados con el bienestar y el desarrollo de la sociedad. En este trabajo se enfatiza el tránsito entre políticas e instituciones centralizadas, coyunturales y sectoriales, hacia aquellas que buscan el desarrollo local y la atención de la diversidad y complejidad que de ello deriva, particularmente en los ámbitos de educación, empleo y participación juvenil.

Hernán Camarero, nos presenta en su artículo Una revisión acerca del estudio de la movilización de la protesta y la organización de los movimientos sociales a partir de las teorías de la acción colectiva, un análisis de carácter conceptual acerca de los modos en que los movimientos sociales fueron examinados por la sociología y las teorías de la acción colectiva. En el texto, se problematiza la existencia de una asociación directa entre las tensiones estructurales en una sociedad y la movilización de la protesta como idea que tuvo vigencia durante años en la teoría 
sociológica, concluyendo que, frente a las primeras interpretaciones, se fue avanzando hacia un modelo multifactorial.

Mabel Causarano (Paraguay), titula su artículo Enlazando tradición e innovación; el programa integral de actuación para el Centro Histórico de Asunción (CHA), y comenta que el CHA ha sufrido un proceso de pérdida de la población residente y de centralidad urbana, causados por el desplazamiento de las actividades económicas y de las funciones residenciales, hacia otras zonas de expansión metropolitana, situación que ha provocado su debilitamiento como escenario urbano y símbolo /fundacional de la nación. Presenta el Programa Ciudadela Cultural de Asunción, promovido y coordinado por la Secretaria Nacional de Cultura, para la recuperación del CHA desde la perspectiva de su dinamización como espacio cultural, conectándola a procesos de reactivación económica en los ámbitos del turismo, la economía creativa y la innovación, a partir de un enfoque y una metodología innovadores, basados en el rescate de la memoria colectiva y en la articulación entre instituciones públicas, organizaciones civiles y sector privado.

El artículo titulado Regularización de la tenencia del suelo urbano en Brasil: avances recientes y desafíos de Paulo Avila, muestra como trazo distintivo del proceso de urbanización en Brasil, la proliferación en las ciudades, de asentamientos informales de la población más pobre, en donde la inseguridad de la tenencia de la vivienda está asociada a innumerables problemas sociales. Asimismo traza un panorama de la evolución reciente del marco legal en el nivel federal para la regularización de la tenencia del suelo urbano y discute algunas cuestiones sobre lo que aún necesita ser hecho para mejorar los resultados de las políticas públicas de regularización, como condición para el desarrollo socioeconómico de las áreas urbanas.

Finalmente Sofía Ares, nos presenta el artículo titulado Lejos, Tranquilos y Solos. Experiencias Espaciales en el Partido de General Pueyrredón, cuyo objetivo es comprender los significados del espacio vivido y las tramas de sentido construidas por los sujetos, en tanto contribución original destinada a la ampliación de los conocimientos vinculados con la vida cotidiana y la subjetividad espacial. La identificación de sentidos presupone un análisis minucioso de las narrativas, deconstruyéndolas para luego reconstruir la trama que los sujetos ponen en juego cuando reconocen a un lugar como propio, destacándose el valor de este tipo de indagaciones para la comprensión de los procesos de territorialización, así como la consideración de la subjetividad espacial en la gestión territorial.

Es para mí un honor que las autoridades de la Facultad de Ciencias Sociales de la Universidad de Palermo me hayan dado la posibilidad de organizar y dirigir esta publicación y en este sentido quiero transmitir mi más profundo agradecimiento a la Sra. Decana MBA, M.Ed.S. Elsa Zingman y al Sr. Secretario Académico Lic. Luis Brajterman. Asimismo agradecer profundamente la participación a autoras/autores y evaluadoras/evaluadores que hicieron posible este número.

Dra. Graciela Tonon 
Número 1. Diciembre 2013

Investigar en Ciencias Sociales: El desafío por el análisis científico.

Graciela Castro.

The good society: Defining and measuring wellbeing between complexity and limit.

Filomena Maggino

Reforma y políticas juveniles en México: Avances y retrocesos institucionales.

Karla Valverde Viesca.

Una revisión acerca del estudio de la movilización de la protesta y la organización de los movimientos sociales a partir de las teorías de la acción colectiva.

Hernán Camarero.

Enlazando tradición e innovación. El programa integral de actuación para el centro histórico de asunción.

Mabel Causarano.

Regularización de la tenencia del suelo urbano en Brasil.

Paulo Coelho Ávila.

Lejos, tranquilos y solos. Experiencias espaciales en el partido de general Pueyrredón. Sofía Ares. 